\title{
A Predictive Stock Market Technical Analysis Using Fuzzy Logic
}

\author{
Acheme David Ijegwa ${ }^{1}$, Vincent Olufunke Rebecca ${ }^{1}$, Folorunso Olusegun ${ }^{1} \&$ Olusola Olasunkanmi Isaac ${ }^{2}$ \\ ${ }^{1}$ Department of Computer Science, Federal University of Agriculture, P. M. B. 2240 Abeokuta, Nigeria \\ ${ }^{2}$ Department of Physics, University of Lagos, Nigeria \\ Correspondence: Vincent, O. R., Department of Computer Science, Federal University of Agriculture, P. M. B. \\ 2240 Abeokuta, Nigeria. E-mail: vincent.rebeccca@gmail.com
}

Received: March 29, $2014 \quad$ Accepted: April 28, $2014 \quad$ Online Published: July 5, 2014

doi:10.5539/cis.v7n3p1 URL: http://dx.doi.org/10.5539/cis.v7n3p1

\begin{abstract}
Decision making process in stock trading is a complex one. There are numbers of technical indicators that are used by traders to study trends of the market and make buying and selling decisions based on their observations. This research seeks to deploy fuzzy inference to stock market, with four indicators used in technical analysis to aid in the decision making process in order to deal with probability. The four technical indicators are the Moving Average Convergence/Divergence (MACD), Relative Strength Index (RSI), Stochastic Oscillator (SO) and On-Balance Volume (OBV). The fuzzy rules are a combination of the trading rules for each of the indicators used as the input variables of the fuzzy system and for all the four technical indicators used, the membership functions were also defined. The result is a recommendation to buy, sell or hold. Data were collected for two Nigerian banks for testing and evaluation of the system. The technical indicators were then computed for each data and from the computed technical indicators; experiment was carried out for two months. The system generated satisfactory recommendation as when to buy, sell or hold, when the output is compared with actual data collected from the Nigerian Stock Exchange. The system can therefore act as an effective model for traders in the stock market when there is a combination of the recommendation with the individual's trading skills.
\end{abstract}

Keywords: stock market, technical analysis, fuzzy logic, technical indicators, complex system

\section{Introduction}

\subsection{Problem Statement}

The stock market is one of the most attractive places for investment, especially for traders as it provides a good market place for both long term and short term investment for profit making. It is also important for companies, because this is one of their primary sources to raise money. However, stock trading is very risky, the decision making process in stock trading is a very critical and important process because it must be taken correctly and in the right time (Ahmed, Raaffat, \& Nevins 2007). The stock market is also a popular investments destination owing to its high expected profit. However, the recent experienced showed that the higher the expected profit, the higher the risk implication. (Kou, Chen, \& Hwang, 2001; Vincent \& Bamiro, 2013) Thus, numerous investigations gave rise to different decision support systems for the sake of providing the investors with an optimal prediction. With the huge availability of stock information, made possible by the internet, the task of the investor has been made more difficult, as he will have to collect, analyse, filter and make correct decision from several information. The information includes financial historical information, real time information and economical information opined that in order to successfully trade in the financial markets, it is important to develop models where one can identify different states of the market so as to modify one's actions (Jan, Uzay, \& Willien, 2004).

A study observed different models that have been developed over the years to understand, monitor and predict the stock market; these models belong to the family of stochastic models and included ARCH, GARCH and statistical volatility models (Nicholis \& Sumpter, 2011). Apart from the statistical models that have been used to understand and predict fluctuations in the stock market, a lot of attention has also been shifted to the applications of various artificial intelligence techniques to the stock market as observed by Preethi and Santhi (2012). Many researchers have also focused on technical analysis as the procedure to improve the investment rate in stock market (Cheung \& Kaymak, 2007; Ahmed et al., 2007; Dourra \& Siy, 2002; Simutis, 2000, Refenes, Burgess, \& Bentz, 1997; Sotiris, Skiada, \& Jiannis, 1999; Lin, Chin-Shien, Khan, Ali, Huang, \& Chi-Chung, 2002); Zhou, 
Xu, Shen, Don, \& Ming, 2004).

Therefore, understanding the market and being able to tell what will happen at the near future are desirable skills for every investor (Potvin, Soriano, \& Vallée, 2004). This research proposes to attack this impending problem of investment using a simple inference indicators' model with few variables to simplify the complex market environment in order to make reliable recommendations for the investors, and thus providing a valuable decision support tool. The work employs fuzzy logic to perform the decision making process, based on inputs from technical analysis indicators.

\subsection{Revision of Methods for Stock Market Prediction}

Several techniques have been applied to studying and understanding the stock market, these methods can be classified into statistical methods, artificial agent-based market simulations and artificial intelligence techniques.

\subsubsection{Statistical Methods}

Nicholis and Sumpter (2011), observed different statistical models that have been developed over the years to understand, monitor and predict the stock market. These models belong to the family of stochastic models and include ARCH, GARCH and statistical volatility models. GARCH stands for Generalized Autoregressive Conditional Heteroscedasticity. The word "autoregressive" indicates a feedback mechanism that incorporates past observations into the present. The word "conditional" indicates that variance has a dependence on the immediate past. The word "heteroscedasticity" indicates a time-varying variance (volatility). GARCH models, introduced by Bollerslev (Bollerslev, 1986), generalized Engle's earlier ARCH models (Engel \& Robert, 1982) to include autoregressive (AR) as well as moving average (MA) terms. These models assume that the variance of the current market returns is a function of the magnitude of the previous returns.

\subsubsection{Agent-based Modeling Methods}

Another approach that has also emerged is the agent-based modeling of stock markets, which originated at the Santa Fe Institute (Palmer et al., 1989). Artificial stock markets are models of financial markets used to study and understand market dynamics. They can be seen as any market models in which prices are formed as a result of participants' interaction. Palmer, Brain, Holland and LeBaron (1994) provided the first instance of an artificial stock market, the Santa Fe stock market model which they presented consisted of a central computational markets and a number of agents. The agents would notice patterns in the price, form models and then trade on that basis. Lux and Marchesi (2000) focused on the case of limited agents. It modelled agents in groups and the groups switch from various types of traders (optimist to pessimist or vice versa) in response to observed differences in profits. Other agent-based models can be found in Chen and Chung-Chi (2005); Zou et al. (2005); Ozun (2006); Feng et al. (2012) and Kato (2012).

\subsubsection{Artificial Intelligence Methods}

Apart from the statistical and agent based models that have been used to understand and predict the stock market, a lot of attention has also been shifted to the applications of various artificial intelligence techniques to the stock market recently. Preethi and Santhi (2012) presented a survey of various techniques in the field of artificial intelligence aimed at better understanding and predicting stock indexes. The most popular have been neural networks, data mining and neuro-fuzzy systems (Preethi \&d Santhi, 2012).

Ahmed, Raaffat and Nevins (2007) proposed a fuzzy logic based decision support system that would help investors of the stock market to make the correct buy/sell/hold decisions. Their work uses fuzzy logic and technical analysis techniques to perform the decision making process. Actual data of the NASDAQ index was used for simulation. The major drawback of their research was the used of only Moving Average (MA) technical indicator in the formation of rules for the fuzzy inference system. A better reliable result could have been obtained if several technical indicators were combined. Since technical analysis deals with probability, combination of different indicators is necessary to improve the result.

Chueng and Kaymak (2007) examined a trading model that combines fuzzy logic and technical analysis to find patterns and trends in financial indices. The proposal was designed to distinguish various regimes in the market and generate a buy or sell signals for traders who have to invest in a mix of European, American and Japanese bond and currency. Their work combined four different technical indicators to form the rules for the fuzzy inference system, the results generated were satisfactory, but, their work was limited only to trading of foreign currencies (FOREX).

Hemanth, Prashant, Nirmala and Basavaraj (2012) showed the use of hybrid systems to study a synergetic combination of methods. The work presented a neuro-fuzzy based technique for predicting financial time series. 
It showed that it performed well in the context of various trading strategies involving stocks. The stock market closing data from the BSE Sensex from $17^{\text {th }}$ September, 2007 to $9^{\text {th }}$ March, 2012 was used, and the work was implemented using the Adaptive Network-Based Fuzzy Inference System (ANFIS). Melek and Derya (2010) also used the same techniques (ANFIS) to study the Istanbul Stock Exchange.

Chang and Liu (2003) also presented a Takagi-Sugeno-Kang (TSK) type fuzzy rule based system for stock prediction. The model developed, applied the technical index of the Taiwan stock market as the input variables. They tested the model on the Taiwan electronic shares from the Taiwan Stock Exchange; the model successfully forecasted the price variation for stocks from different sectors. Yun et al. (2013) presented a machine learning algorithm with wrapped ensemble approach using a supervised learning algorithm to predict China's stock. Their work showed that machine learning performed better than traditional statistical methods of predicting stock indices.

Several other researchers have used the neural network for solving this problem as well. (Theodorus \& Dimitris, 2013; Chen, Leung, \& Daouk, 2003; Tang, Xu, Wan, \& Zhang, 2002; Asakwa, 1990; Refenes et al, 1997, Hemanth et al, 2012). In addition, the use of genetic programming has been reported in the literatures, (Shangkum \& Sakurai, 2013; Halina \& Marcin, 2001; Li \& Tsang, 1999; Maniadakis \& Surmann, 1999). Their results as reported by (Ahmed, 2007) were more satisfactory and efficient than other statistical methods used for stock prediction. However, in this research work we apply fuzzy logic control for the following reasons as outlined by (Dourra \& Siy, 2002):

1. Neural network based system lack perceived reliability in its judgement. There is no way to determine if a training set is adequate or not

2. In most cases, the answer by technical indicators is not a definite yes or no, this implies yes or no logic stops being helpful, fuzzy reasoning is very effective in such environments.

3. The rules are expressed in English-like structure, which corresponds more to the human way of thinking.

4. Fuzzy logic is more flexible than an expert system because fewer rules are used and their combination is required to cover more possible outcomes.

5. Fuzzy inferences can handle and correct overlap or ambiguity between rules.

6. A fuzzy system is considered majority in this work because it is more modular and open to modifications than AI techniques like the Neural Network based trading systems.

Fuzzy logic based systems have been around for quite some time and have been widely used in expert systems, home appliances like microwaves and vacuum cleaners, robotics, and machinery. Recently, applications in the finance field have also been reported by Cheung and Kaymak (2007), exploiting the ability of fuzzy systems to model the vague and imprecise information generated from financial markets. The formation of fuzzy rules is a very important step in developing fuzzy systems; some researchers acquire these rules from experts. Alcala, Casillas, Cordon, Herrera and Zwir (1999) gives an overview of different approaches for learning fuzzy rules. Francisco, Manuel and Verdegay (1994) proposed a method to learn the rules using a genetic algorithm. In this work, we have learned the fuzzy rules for chosen technical indicators from experts and available literature on technical analysis theory.

Dourra and Siy (2002) proposed a very close method to map technical indicators with fuzzy system in order to predict buy, hold and sell periods. However, the work made use of three momentum technical indicators, the Rate of Change, Stochastic Oscillator and Support Resistance indicator. These three indicators only considered price changes over trading period without consideration for traded volume. In this work therefore, we extend the technical indicators to four, adding the On-Balance Volume indicator which considers traded volume over the trading period. This work is designed:

1. To map different financial indicators into new inputs that can be "fuzzified". These indicators are Moving Average Convergence/Divergence (MACD), Stochastic Oscillator (SO), Relative Strength Index (RSI) and the On-balance Volume.

2. To create membership functions to associate between inputs and outputs via fuzzy rules

3. To translate the fuzzy output into crisp trading recommendation of buy, sell or hold that can be used by a trader in the stock market.

\section{Design of the Fuzzy Logic-Based Stock Prediction System}

The system architecture is outlined in Figure 1, in which three modules are identified: the technical analysis 
module, the convergence module and the fuzzy inference module. The technical analysis module, takes in the historical stock prices and calculates for each series the four technical indicators. The convergence module transforms the technical indicators into new auxiliary variables so that they are used as inputs for the fuzzy inference system. The difference between the MACD signal and the trigger signal is computed and used as input to the fuzzy system. Some indicators can lead to multiple inputs to the fuzzy system. But in this work, we have mapped each indicator to one input, to keep the model simple. The output of this convergence module serves as the input variable for the fuzzy inference system and the fuzzy inference System (FIS) module generates a trading signal based on the rules defined in the rule base.

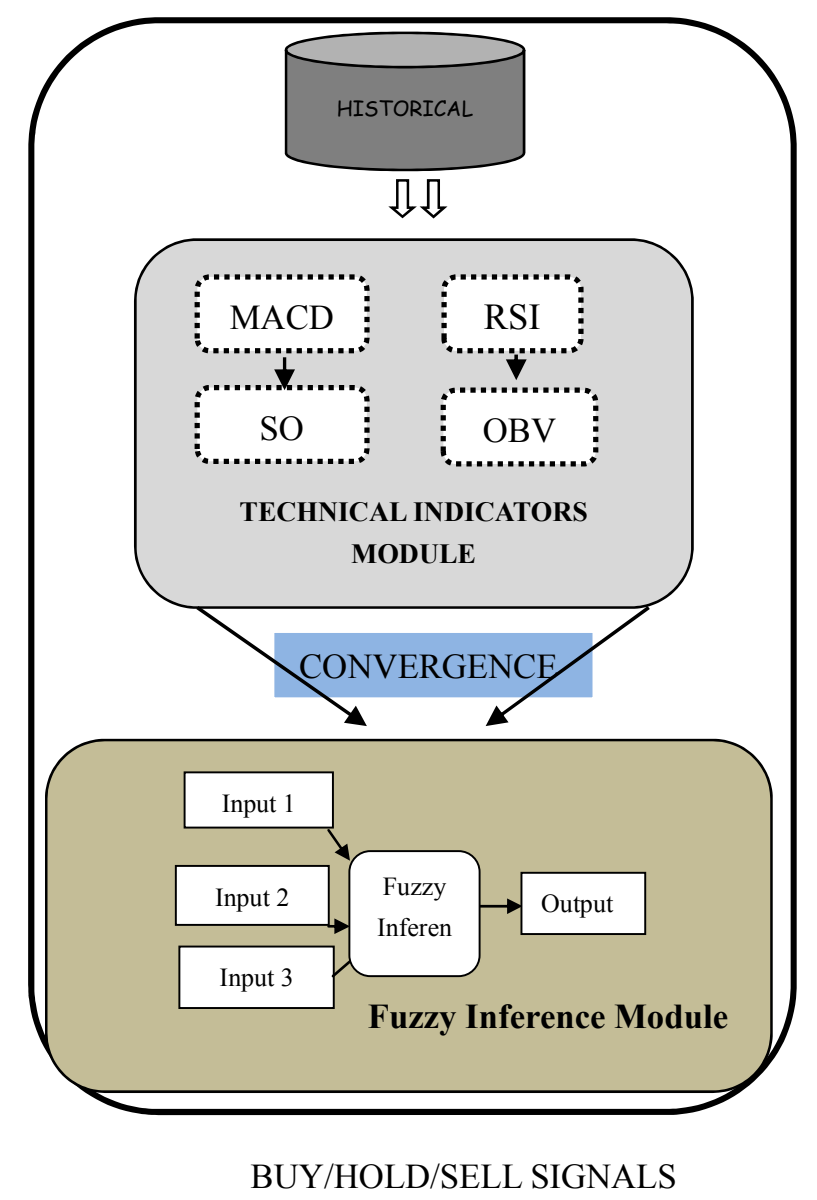

Figure 1. Fuzzy Logic-Based Stock Prediction System

\subsection{Technical Analysis Module}

Technical analysis was developed around 1900 by Charles Dow (Achelis \& Stephen 2000). It is an approach used by experts to make decision in the stock market. It is based on analysing security prices, the price of a security is the price at which one investor agrees to buy and the price at which another agrees to sell. Ahmed et al (2007) defined it as a process of analysing a security's historical prices in an effort to determine probable future price (Fernández-Rodríguez, González-Martel, \& Sosvilla-Rivero, 2000; Ince \& Trafalis, 2008). In technical analysis, analysts look for patterns, trends and other factors that may be present in financial stock market prices. These patterns and trends may be able to effectively predict stocks' future performances and hence can be used to make a buy or sell decision.

The factors are usually defined as indices derived from existing data following a particular kind of reasoning, which is usually based on heuristics (Cheung \& Kaymak, 2007). Although, there are disagreements about the effectiveness of technical analysis, various studies have reported that technical analysis possesses better predictive power than other statistical methods. (Brock et al., 1992). Therefore, this work chooses the following four technical indices identified to have higher predictive powers:

Moving Average Convergence/Divergence (MACD). 
- $\quad$ Relative Strength Index (RSI).

- $\quad$ Stochastic Oscillator (SO).

- $\quad$ On-Balance Volume (OBV)

These technical indexes were used along with domain expertise given by financial institution experts with definition of rules for the fussy system.

\subsubsection{Moving Average Convergence/Divergence (MACD)}

This is a technical analysis indicator created by Gerald Appel in the late 1970s. It is one of the most well-known and used indicators in technical analysis. This indicator comprises of two exponential moving averages, which help to measure momentum in the security. The MACD is simply the difference between these two moving averages plotted against a centreline. When the MACD is positive, it signals that the shorter term moving average is above the longer term moving average and suggests upward momentum. The opposite holds true when the MACD is negative - this signals that the shorter term is below the longer and suggest downward momentum. When the MACD line crosses over the centreline, it signals a crossing in the moving averages.

In this work, the most common moving average values are used in the calculation. These are the 26-day and 12-day exponential moving averages (Achelis \& Stephen, 2000). The signal line is created by using a nine-day exponential moving average of the MACD values. These values can be adjusted to meet the needs of the technician and the security. In constructing a MACD for any given stock or underlying security, the following will be calculated:

(i) A 12 day EMA of closing prices

(ii) A 26 day EMA of closing prices

(iii) Subtract the longer EMA in (2) from the shorter EMA in (i)

(iv) A 9 day EMA of the MACD line gotten in (iii)

$$
E M A=\operatorname{Price}(t) * k+E M A(y) *(1-k)
$$

Where $t$ represents today, $y$ denotes yesterday, $N$ is the number of days in EMA and $k=2 /(N+1)$. The crossing of line is usually used to indicate a buy or sell signal. This indicates that a buy signal is generated when the MACD crosses above the signal line, while sell signal occurs when the MACD crosses below the signal. The trading rules of the MACD to be used in the fuzzy inference system are:

IF MACD is above the signal line THEN BUY

IF MACD is below the signal THEN SELL

\subsubsection{Relative Strength Index (RSI)}

The Relative Strength Index (RSI) considers whether an asset is over bought or oversold. RSI is describes in equation 2 .

$$
R S I=100-\frac{100}{(1+R S)}
$$

Where $R \mathrm{~S}$ is average of $n$-day up closes/ average of $n$-day down closes; $n$ is the number of days though, most analysts use 9 - 15 days RSI. In order to get a fair display of the property, 14 days is used in this work. The RSI ranges from $u$ to 100 . Different sectors and industries have varying threshold levels when it comes to the RSI. Stocks in some industries will go as high as 75 to 80 before dropping back and others have a tough time breaking past 70. The following classification rules were used in this work:

IF RSI increases to above 70 (implies overbought) THEN SELL.

IF RSI is between 30 and 70 (implies normal) THEN HOLD

IF RSI decreases to below 30 (implies oversold) THEN BUY

\subsubsection{The Stochastic Oscillator (SO)}

The Stochastic Oscillator gives an indication of the stock's last closing price relative to the stock's recent trading range (Hussein \& Dourra, 2002). This is one of the most recognized momentum indicators used in technical analysis. The SO is plotted within a range of 0 to 100 and signals over-bought conditions above 80 and oversold conditions below 20 (Achelis \& Stephen, 2000). It contains two lines, the first line is the $\% K$, which is a 
measure used to formulate the idea of momentum behind the oscillator. The second is the $\% D$, which represents a moving average of $\% K$. The two variables $\% K$ and $\% D$ are shown in equations 3 and 4 .

$$
\begin{aligned}
& \% K(n T)=\left(\frac{R(n T)-R_{\min }(n T)}{R_{\max }(n T)-R_{\min }(n T)}\right) 100 \\
& \% D(n T)=\sum_{(n-3)}^{n} \frac{\% K(n T)}{3}, \quad n \geq 3
\end{aligned}
$$

Where $R_{\min }(n T)$ is the minimum $R(n T)$ over a trading period; $R_{\max }(n T)$ is the maximum $R(n T)$ over a trading period, $\% K$ is the momentum behind the oscillator, $\% \mathrm{D}$ is the moving average of $\% K, n$ is the number of trading period in time $\mathrm{T}$. The trading rules of the stochastic oscillator is summarized as follows:

IF SO increases above 80 (implies overbought) THEN SELL

IF SO is between 20 - 80 (implies normal) THEN HOLD

IF SO is below 20 (implies oversold) THEN BUY

\subsubsection{On-Balance Volume (OBV)}

This technical indicator reflects movements in volume of stocks. The OBV is calculated by taking the total volume for the trading period and assigning it a positive or negative value depending on whether the price is up or down during the trading period. When there is a rise in the prices at the trading period, the volume is assigned a positive value, while a negative value is assigned when the price is down for the period. The positive or negative volume total for the period is then added to a total that is accumulated from the start of the measure. While studying the OBV, it is more important to focus on the trend in the OBV than the actual value of the OBV measure. On Balance Volume is calculated by adding the day's volume to a cumulative total when the security's price closes up, and subtracting the day's volume when the security's price closes down. If today's close is greater than yesterday's close then

$$
O B V=\text { Yesterday's } O B V+\text { Today'sVolume }
$$

Else, If today's close is less than yesterday's close then:

$$
O B V=\text { Yesterday's } O B V-\text { Today'sVolume }
$$

Else, If today's close is equal to yesterday's close then:

$$
O B V=\text { Yesterday's } O B V
$$

The trading rules for this indicator can be of the following form:

\section{IF line is Upward then BUY}

Else IF line is Downward then SELL

The parameters for the technical indicators are specified according to the default guidelines in technical analysis. For the MACD indicator, 26 and 12 weeks are used as the long-term and the short-term moving average, respectively. The trigger line for the MACD is the 9 weeks moving average of the MACD. The RSI indicator uses a period of 20 weeks. Table 1 summarizes the parameters used in the technical indicators module.

Table 1. Technical Indicator Parameters

\begin{tabular}{ll}
\hline Technical Indicator & Parameters \\
\hline MACD & Long $=26$ \\
& Short $=12$ \\
& Trigger $=9$ \\
RSI & $\mathrm{N}=14$ \\
Stochastic Oscillator & $\mathrm{K}=10$ \\
OBV & $\mathrm{D}=3$ \\
& Moving Average Method = exponential \\
& Upward = Buy \\
& Downward = Sell \\
\hline
\end{tabular}




\subsection{Convergence Module}

The convergence module transforms the technical indicators into new auxiliary variables so that they are used as inputs for the fuzzy inference system. The difference between the MACD signal and the trigger signal can be computed and used as input to the fuzzy system. Some indicators can lead to multiple inputs to the fuzzy system. But in this work, we have mapped each indicator to one input in order to keep the model easy. The output of the convergence module serves as the input variable for the fuzzy inference system. Table 2 shows the input variables as well as associated membership functions.

Table 2. Input Variables for the Fuzzy Inference System

\begin{tabular}{lll}
\hline Input Variable & Membership Function & Range \\
\hline MACD & Low and high & $\begin{array}{l}\text { Low when is below signal line and high when is above } \\
\text { signal line }\end{array}$ \\
RSI & Low, medium and high & $\begin{array}{l}\text { Low when RSI value is below } 30, \text { medium when between } \\
30 \text { and } 70 \text { and high when above } 70\end{array}$ \\
SO & Low medium and high & $\begin{array}{l}\text { Low when SO value is below } 20, \text { medium when between } \\
20 \text { and } 80 \text { and high when above } 80\end{array}$ \\
OBV & Low and high & $\begin{array}{l}\text { Low when trend is downward and high when trend is } \\
\text { upward }\end{array}$ \\
\hline
\end{tabular}

\subsection{Fuzzy Inference System (FIS)}

The fuzzy inference system is based on the types of rules as discussed. The implementation was made as a Mamdani Fuzzy Inference System (FIS) as presented in Alejandro et al, (2013) with Gaussian membership functions used for the input and triangular membership functions for the output. We defined two membership functions for two of the input variables (MACD and OBV) while for the other two; we defined three membership functions each. The output from the fuzzy logic system will be a buy, sell or hold signal based on the rules defined in the rule base. The output of the fuzzy system is a signal on a normalized domain, on which three different fuzzy sets; SELL, BUY, and HOLD are defined.

\subsubsection{Fuzzy Rules}

Generally speaking, there are three main types of decisions: riskless choice, decision making under uncertainty, and risky choice. With this system, we are trying to employ a decision making under uncertainty (Yates, 1990). The distinction between risk and uncertainty hinges upon whether probabilities are known exactly or whether they must be judged by the decision maker with some degree of imprecision (Dourra \& Siy, 2002). Decisions are made based on fuzzy rules. These rules are characterized by a collection of fuzzy IF-THEN rules in which the preconditions/post-conditions involve linguistic variables. This collection of fuzzy rules characterizes the behaviour of the system in a linguistic form that is close to human way of thinking. After establishing a set of rules and membership functions that demonstrate feasibility, the designer can refine the system by experimenting with different rules and membership functions to achieve adequate results. The general form of the fuzzy rules in case of multi-input-single-output systems (MISO) is:

$$
\text { IF } Y_{1} \text { is } A_{1} \ldots \ldots \ldots \text {.... AND OR } Y_{M} \text { is } A_{M} \text { THEN } C \text { is } A_{L}
$$

IF $Y_{1}$ is $A_{1} \ldots \ldots \ldots A N D / O R Y_{M}$ is $A_{M}$ are the preconditions and $\mathrm{C}$ is the post-condition, $Y_{1}$ and $Y_{M}$ are input variables, $C$ is the output variable, $A_{1}$ is the class defined on $Y_{1}, A_{M}$ is the class defined on $Y_{M}$ and $A_{L}$ is class defined on $C$. Lin and Lee, (1996). The antecedent (the rule's premise) describes to what degree the rule applies, while the conclusion (the rule's consequent) assigns a membership function to the output variable. The output variable is assigned a range between $\operatorname{Inf}(C)=0$ and $\operatorname{Sup}(C)=100$. A low value represents excellent opportunity to sell the stock and a high value represents excellent opportunity to buy the stock. The fuzzy rules are a combination of the rules already stated above for each of the technical indicators was extracted from technical trading experts. The rules are as follows: 
IF MACD is HIGH and RSI is MED and SO is MED and OBV is HIGH THEN BUY.

IF MACD is LOW and RSI is MED and SO is HIGH and OBV is LOW THEN SELL

IF RSI is LOW and SO is LOW and OBV is HIGH THEN BUY

IF RSI is HIGH and SO is HIGH and OBV is LOW THEN SELL

IF MACD is LOW and RSI is HIGH and SO is HIGH THEN SELL

IF MACD is LOW and RSI is MED and SO is MED THEN HOLD

IF MACD is HIGH and RSI is MED and SO is MED and OBV is LOW THEN HOLD

\subsubsection{Defuzzification}

Defuzzification is a mapping process from a fuzzy space defined over an output universe of discourse into a non-fuzzy (crisp) action. The method adopted in this paper is centre of area (COA).

$$
F(n T)=\frac{\sum_{i}^{L} \mu C\left(Z_{i}\right)\left(Z_{i}\right)}{\sum_{i}^{L} \mu C\left(Z_{i}\right)}
$$

Where $L$ represents the number of quantization levels of the output $C, Z_{i}$ is the amount of control output at the quantization level $i \mu C\left(Z_{i}\right)$ represents the membership value in the output fuzzy set. This calculation implies that for a specific $R(n T)$ input value, a fuzzy value $F(n T)$ will be created. When $F(n T)$ is close to 100 (high end), the stock is a strong buy. While if $F(n T)$ is close to 0 (low end) the stock is strong sell.

\section{Results}

The result from the fuzzy inference system implemented in the MATLAB is given in Figures 2 to 6 . The interfaces for the input/output variables, membership functions, the rules set, rule viewer and surface viewer are shown respectively.

\subsection{Input and Output Variables}

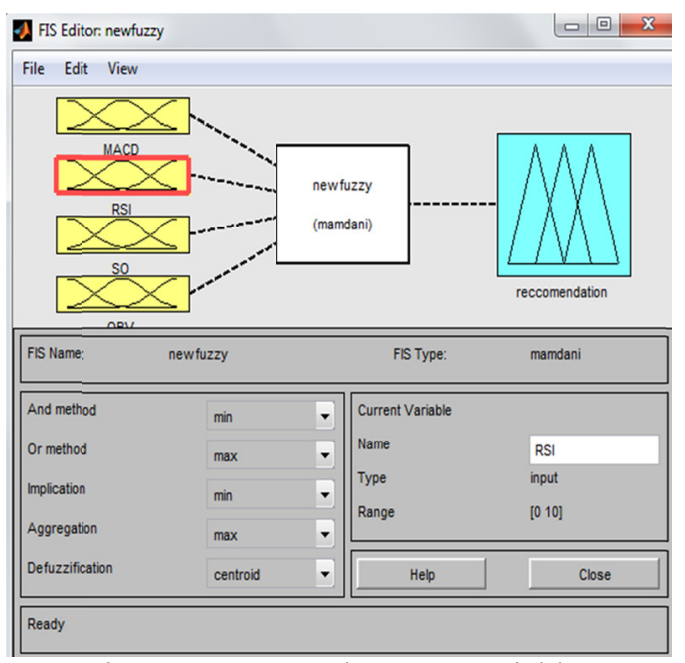

Figure 2. Input and Output Variables

Figure 2 shows the input and output variables which mapped MACD, RSI, SO and OBV directly as fuzzy input variables. The output is a signal on a normalized domain on which the fuzzy sets were defined.

\subsection{Membership Function}

The membership functions defined in Figure 3 shows three membership functions for RSI, OS and the output variable and two membership functions each of MACD and OBV input variables. 


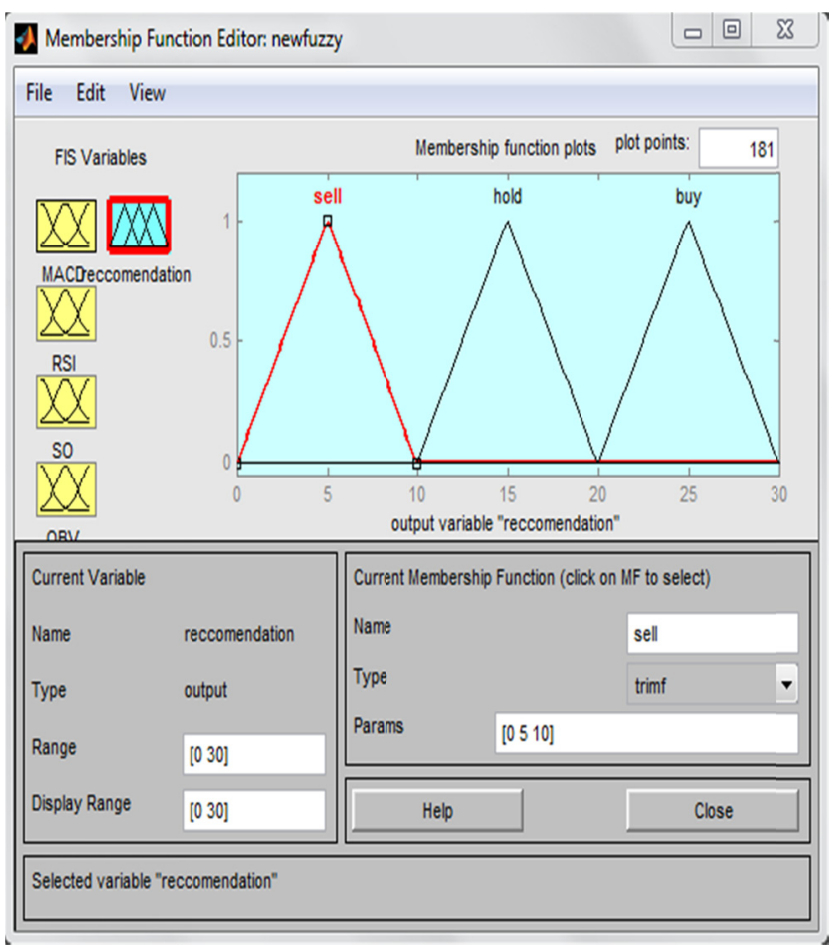

Figure 3. The Membership Function

\subsection{Fuzzy Rules Set}

After defining the membership functions of the fuzzy variables, the rules which will be used by the inference engines to produce the final result were defined as shown in Figure 4. These rules were extracted from technical trading experts. Figure 5 presents the rule viewer which Figure 6 represents the surface viewer of the fussy set.

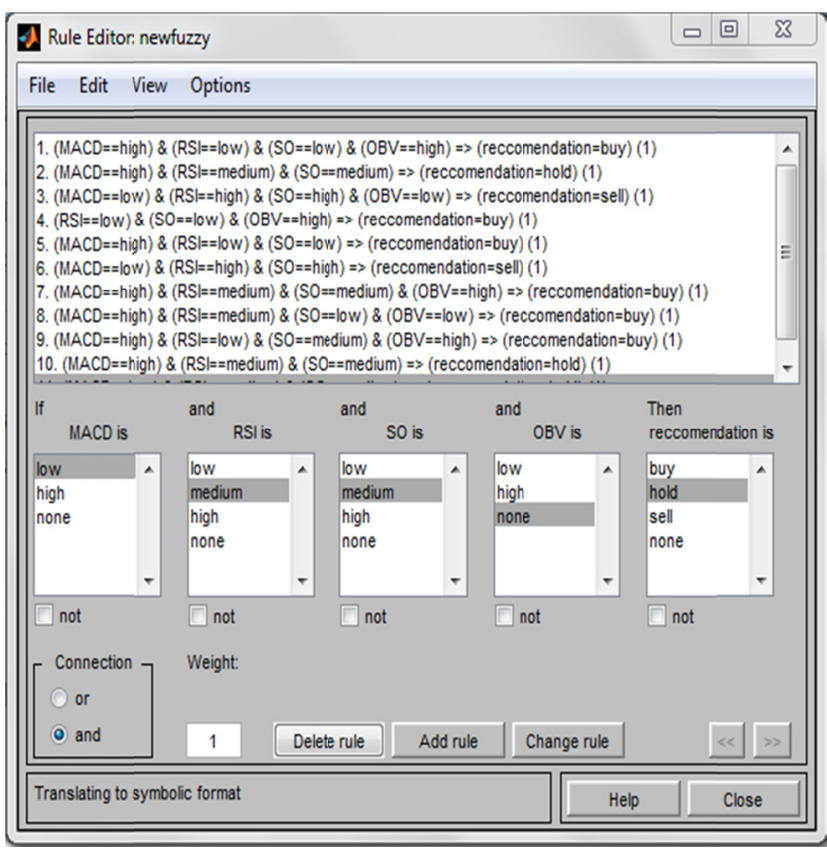

Figure 4. The Rule Editor

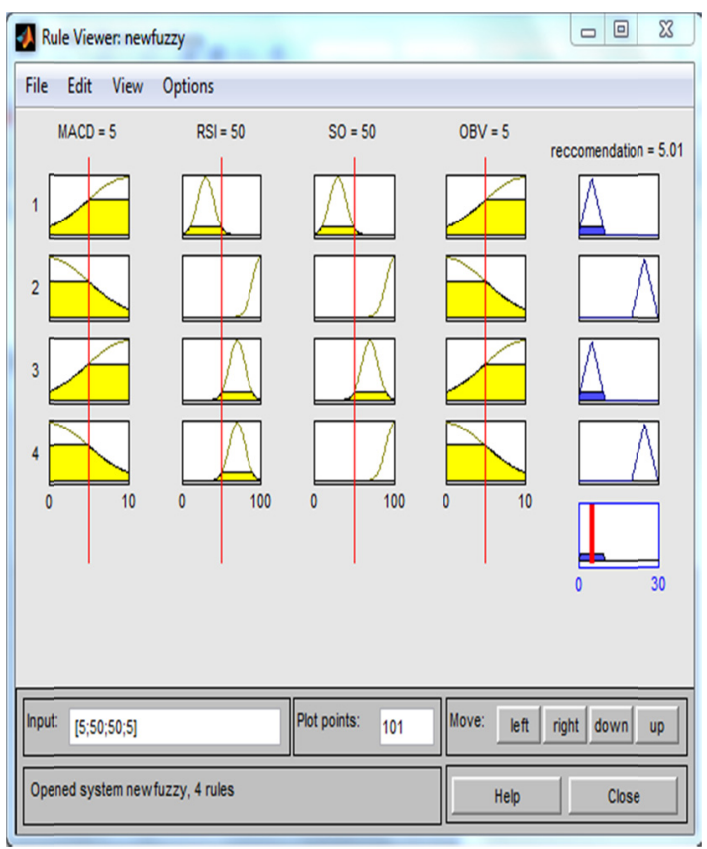

Figure 5. The Rule Viewer 


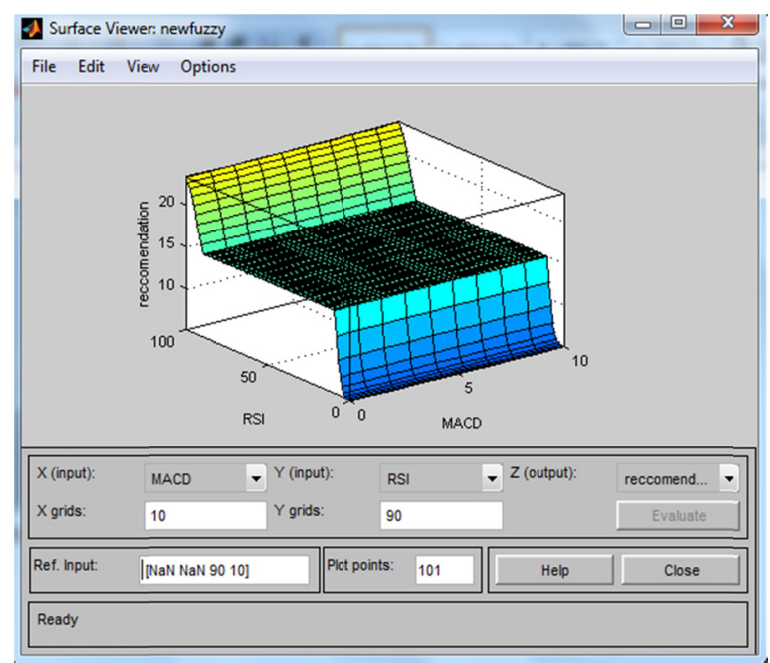

Figure 6. The Surface Viewer

\subsection{System Results}

Data from the Nigerian Stock exchange index was used between the periods of January, 2012 to June 2012 as testing data. This data is the stock historical price and volume of two Nigerian banks. The four technical indicators were computed for each of the bank's data to obtain results. In Figures 7, 8, 9 and 10, the results of MACD, RSI, SO and OBV were predicted respectively for the data set of Bank $A$. MACD, RSI and SO values are plotted against time, while OBV is plotted against traded volume.

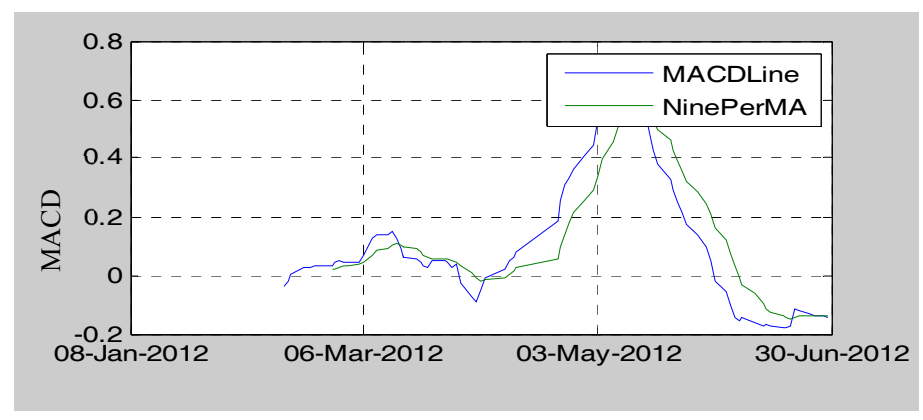

Figure 7. Moving Average Convergence/Divergence for Bank $A$

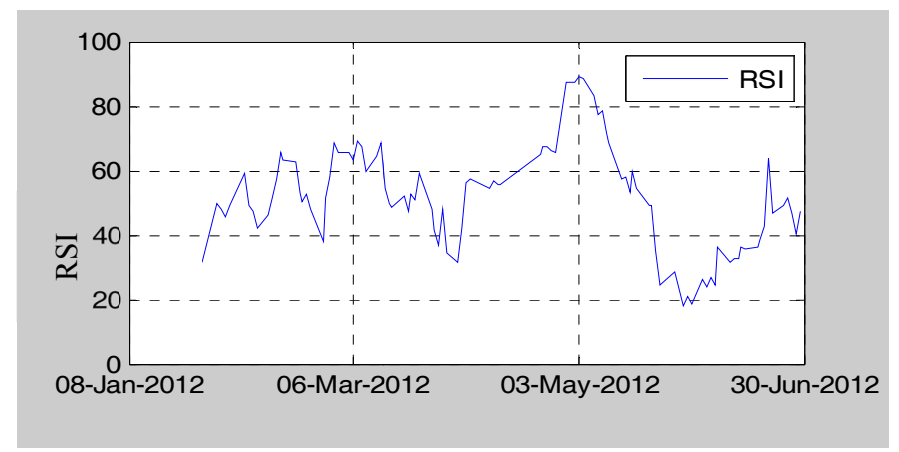

Figure 8. Relative Strength index for Bank $A$ 


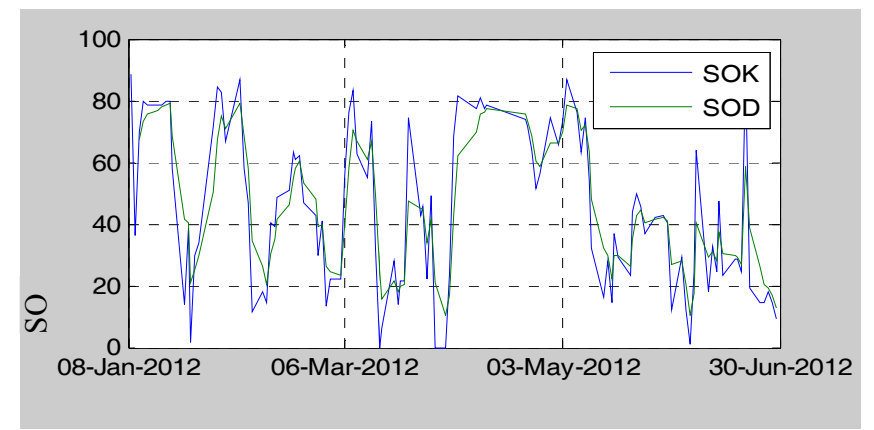

Figure 9. Stochastic Oscillator for Bank $A$

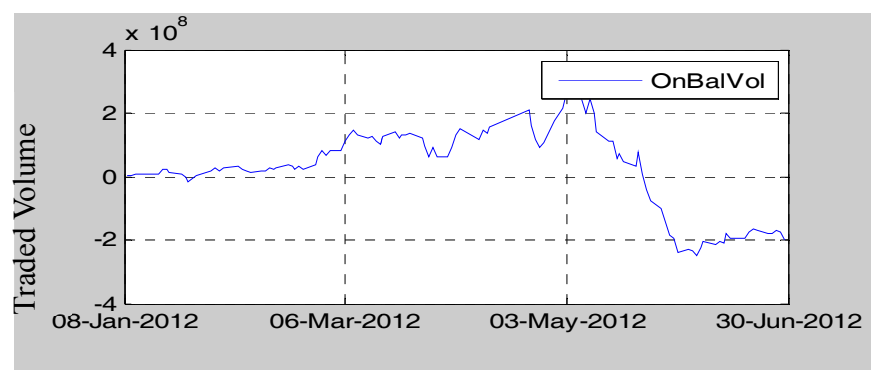

Figure 10. On-Balance Volume Indicator for Bank $A$

From the computed technical indicators, in March 2012, the MACD line was above the trigger line in Table 3 with numerical value of 10 , the RSI was 100 . Stochastic Oscillator also had a value 100 with OBV revealing upward trend, MACD is therefore high. Using these values as inputs into the fuzzy inference system, the recommendation in Figure 11 shows the value 23.4, which means a "buy" as defined in the output membership function.

Table 3. Input/Output Variables for Bank $A$ March, 2012

\begin{tabular}{lllll}
\hline MACD & RSI & SO & OBV & RECOMMENDATION \\
\hline $\mathbf{1 0}$ (above trigger line) & 100 & 100 & 10 (upward trend) & BUY \\
\hline
\end{tabular}

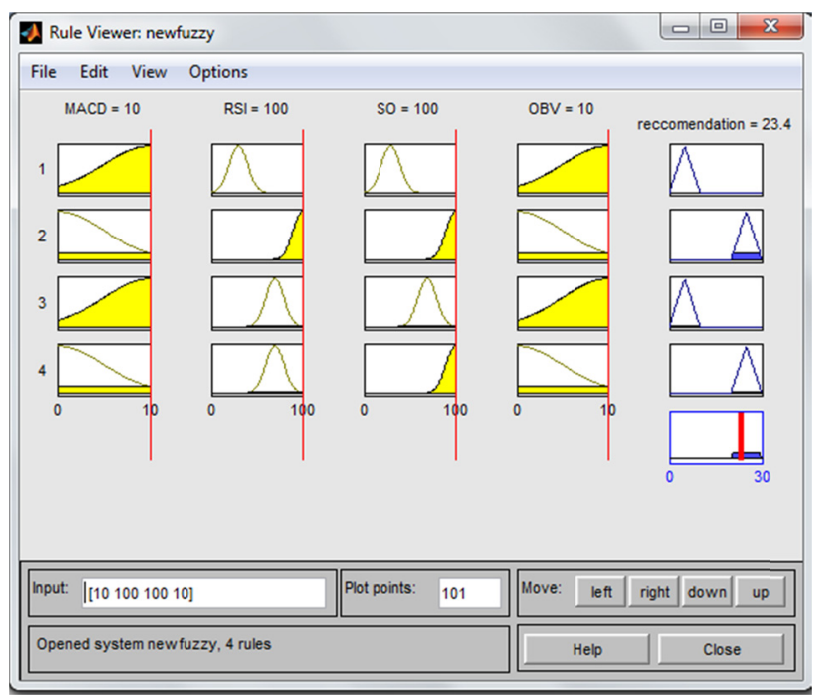

Figure 11. Recommendation for Bank $A$ (March, 2012)

The price fell within this period from 14.11 on the second of March to 13.49 on the 30th of March. Hence, 
buying during this period would have been profitable. The computed technical indicators were further examined for April 2012. The MACD line was below the trigger line, hence low, with a numerical value of 1 , with RSI reading 20. Stochastic Oscillator had the value of 20 and OVB had downward trend, hence low, with numerical value of 1 . These values are summarized in table 4.5 which was the value from the inference system reveal a 'sell'.

Table 4. Input/Output Variables for Bank A April, 2012

\begin{tabular}{lllll}
\hline MACD & RSI & SO & OBV & RECOMMENDATION \\
\hline 2 (bellow trigger line) & 20 & 20 & 2 (downward trend) & SELL \\
\hline
\end{tabular}

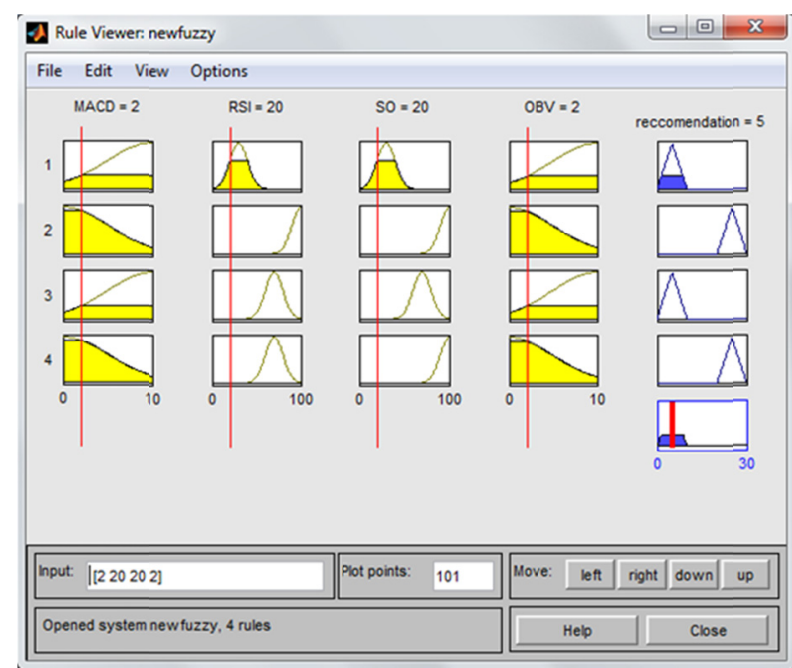

Figure 12. Result for Bank A, April, 2012

Looking at the price movement during this period, observation shows that the price increased from 13.55 on the $2^{\text {nd }}$ to 15.52 on the $17^{\text {th }}$ to 15.98 on the $27^{\text {th }}$. The price increased all through April and selling within this period would have been profitable. There was also an extension experiment to bank $B$. Using data set from bank $B$ for the period between January and June, 2012, MACD, RSI, SO and OBV were computed with simulation results in Figure 13, 14, 15 and 16. Figure 13 shows the moving average convergence/ divergence, Figure 14 presents the relative strength index, Figure 15 displays the stochastic oscillator while Figure 16 gives the on-balance volume indicator for bank $B$. MACD, RSI and SO values were plotted against time, while OBV was plotted against traded volume.

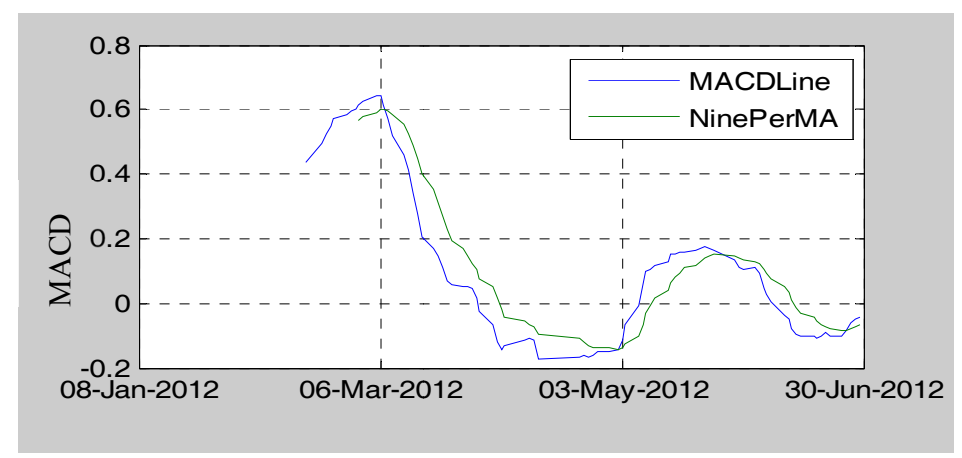

Figure 13. Moving Average Convergence/Divergence for Bank $B$ 


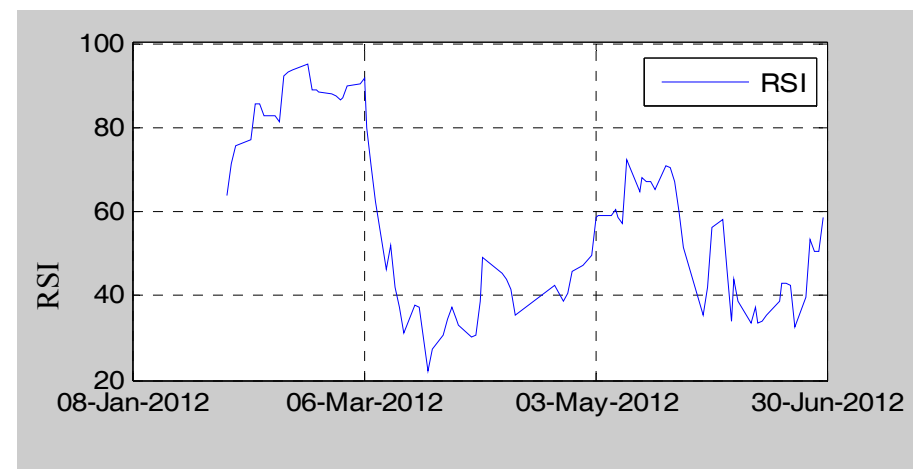

Figure 14. Relative Strength index for Bank $B$

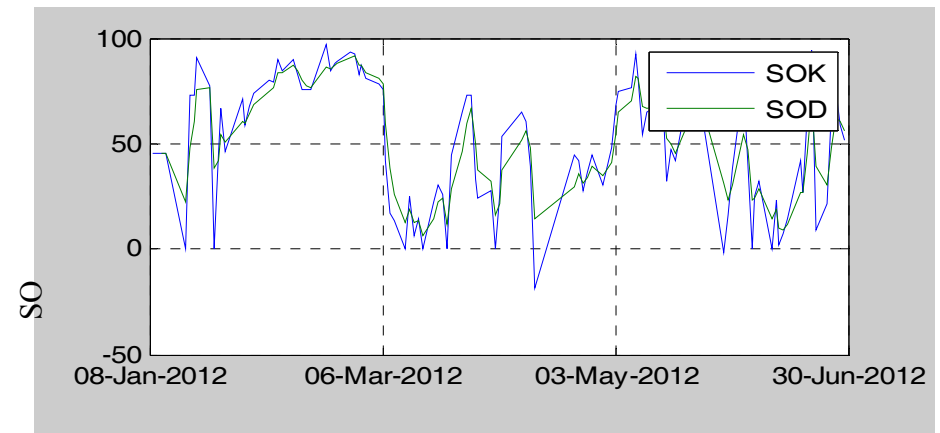

Figure 15. Stochastic Oscillator for Bank $B$

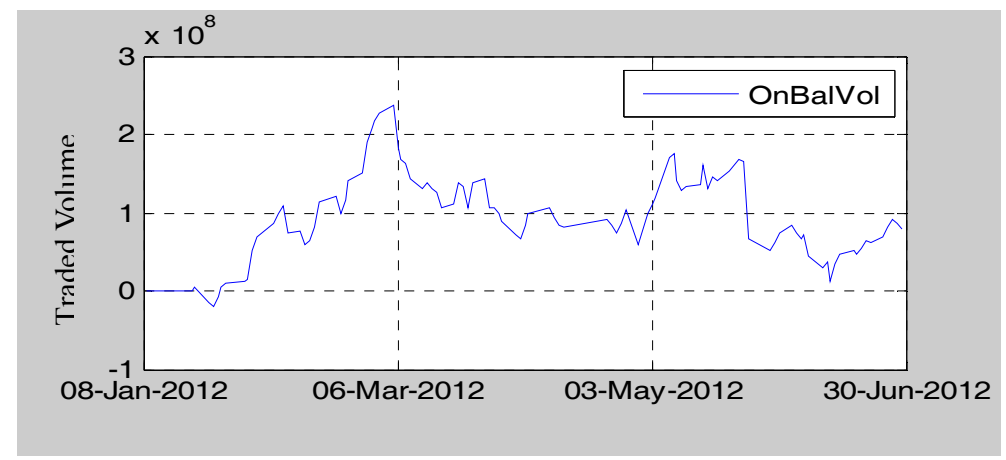

Figure 16. On-Balance Volume Indicator for Bank $B$

From the computed technical indicators, the MACD line was above the trigger line with a numerical value of 10 , the RSI read 80 , Stochastic Oscillator also had the value 80 and OBV had upward trend hence high. Table 5 is a summary of these input variables. Using these values as inputs into the fuzzy inference system, we get the recommendation is presented in Figure 17. The value 23.4 means "buy" as defined in the output membership function.

Table 5. Input/Output Variables for Bank B, March 2012

\begin{tabular}{lllll}
\hline MACD & RSI & SO & OBV & RECOMMENDATION \\
\hline $\mathbf{1 0}$ (above trigger line) & 100 & 100 & 10 (upward trend) & BUY \\
\hline
\end{tabular}




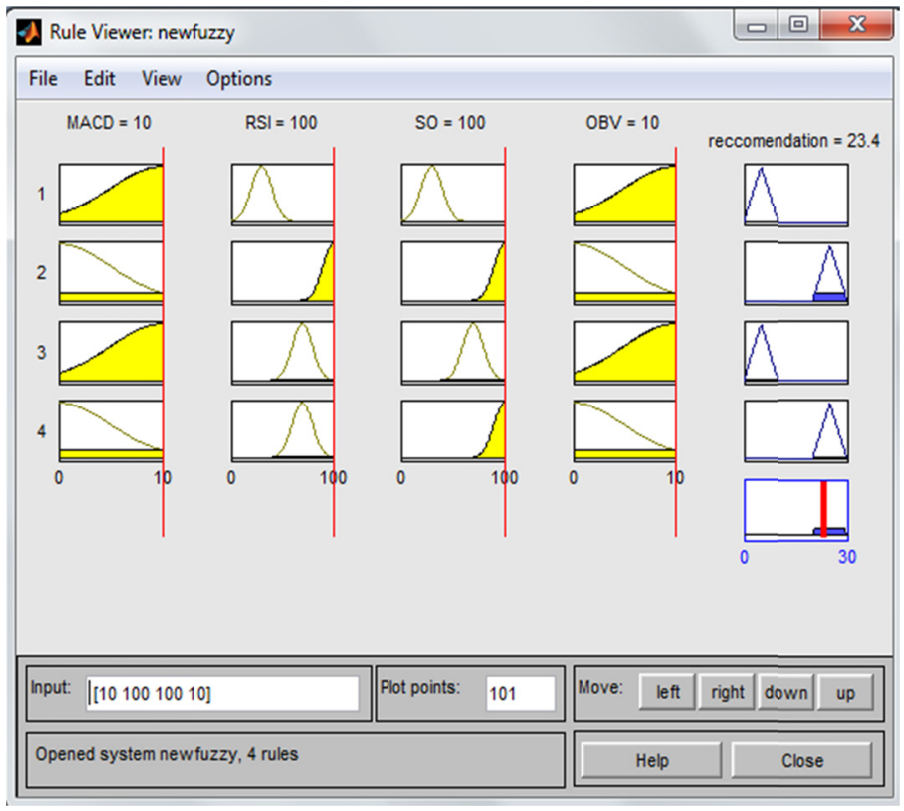

Figure 17. Result for Bank B, March, 2012

An experiment for the month of March, 2012 shows that price fell within this period from 7.5 on the second of March to 5.81 on the 30th of March. Hence, buying during this period would have been hugely profitable. Examination on the month of May has its MACD line was above the trigger line with a numerical value of 10 , RSI was 50, Stochastic Oscillator had the value of 70 and OVB upward trend.. The values are summarized in table 6. Recommendation in Figure 18 is 6.61 which means 'sell'. The price movement during this period shows that the price increased from 6.1 on the $1^{\text {st }}$ of May to 6.66 on the $28^{\text {th }}$ of May. The price increased all through the month of May and selling within this period would have been profitable.

Table 6. Input/Output Variables for Bank B, May, 2012

\begin{tabular}{lllll}
\hline MACD & RSI & SO & OBV & RECOMMENDATION \\
\hline $\mathbf{1 0}$ (above trigger line) & 50 & 70 & 10 (upward trend) & SELL \\
\hline
\end{tabular}

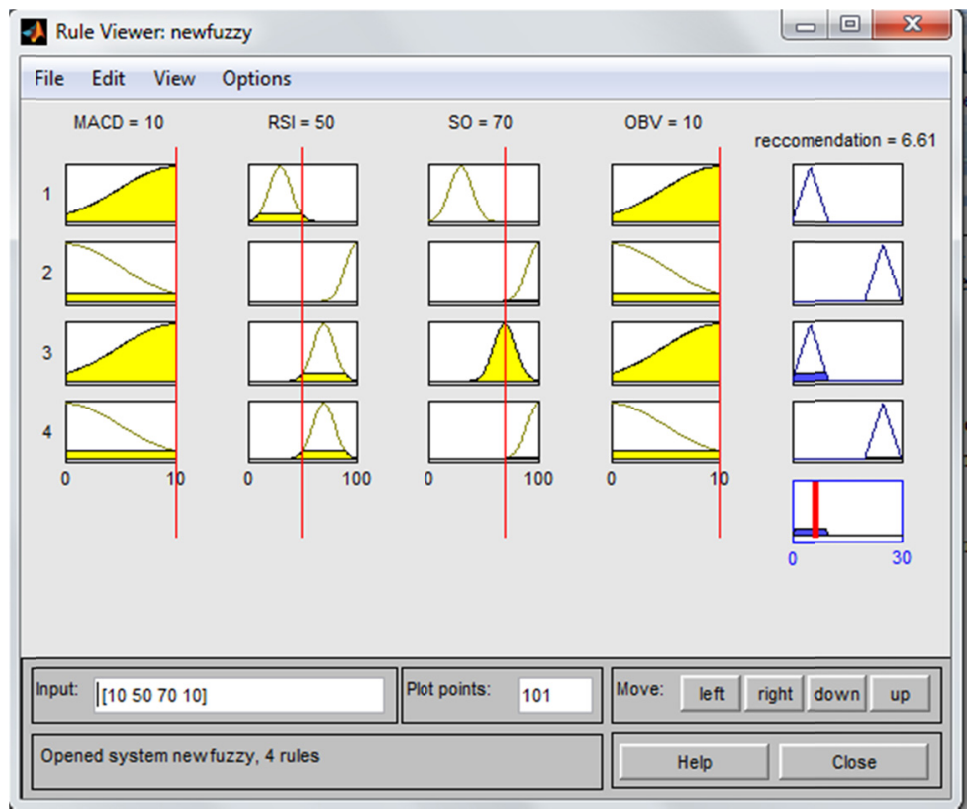

Figure 18. Result for Bank B, March, 2012 


\section{Discussion}

The performance of the system was studied using financial data collected in the period of January, 2012 to June 2012. The data was the daily opening, high, low and closing prices as well as the traded volume of two Nigerian Banks' stock. Thus, a total of 236 data points was available for the analysis. The four chosen technical indicators, MACD, RSI, SO and OBV were computed for the sampled data for each of the bank. These technical indicators are the input variables of the fuzzy system, and the fuzzy rules as well as membership functions were formed based on these technical indicators using domain knowledge of experts in technical trading available in literature. The fuzzy inference method is the Mamdani inference and the output is a recommendation to buy, sell or hold.

For Bank $A$, in the Month of March, 2012, the computed technical indicators, showed the MACD line to be above the trigger line with a numerical value of 10 , the RSI was 100 , Stochastic Oscillator had the value of 100 and OBV had upward trend hence, high with numerical value of 10 . The price of the stock of the bank fell within this period from 14.11 on the second of March to 13.49 on the 30th of March. Hence buying during this period would have been profitable. There was a rise in price all through the month, and selling within this period will have been very profitable. The four technical indicators were computed from the data of Bank $B$. From the computed technical indicators, the MACD line was above the trigger line, during the month of March hence high The recommendation is 23.4 which means "buy" hence, buying during this period would have been hugely profitable.

A stock is considered overbought around the 70 level and one should consider selling. Likewise, if the RSI approaches 30 a stock is considered oversold and one should consider buying. The shorter the number of days used the more volatile the RSI is and the more often it will hit extremes. A longer term RSI is more rolling, fluctuating a lot less. The experiment showed that the system performed satisfactorily in predicting future price movements in the stock market. The aim of the system is not to predict future development in the stock market but merely to identify opportunities and calculate recommendations from the input variables.

\section{Conclusion}

In this work, a method of technical analysis and fuzzy logic as a decision support system for investors in the stock market is proposed. The fuzzy system used as input, information derived from technical analysis charts. The technical indicators chosen are Moving Average Convergence/Divergence (MACD), Relative Strength Index (RSI), Stochastic Oscillator (SO) and On-Balance Volume indicator (OBV). The inputs were created based on these indicators and experiments showed that the system performed satisfactorily in predicting future price movements in the stock market. The system mimics the behaviour of technical traders in interpreting technical indicators. By combining four different technical indicators as inputs, a more reliable system is built.

The system involved mapping the technical indicators as inputs which are "fuzzified", creating membership functions to associate inputs and outputs via fuzzy rules and translating the fuzzy output into crisp trading recommendation of buy, sell or hold. The system consist of three modules, the technical analysis module - where the chosen technical indicators were computed from the sampled data, a convergence module - which transforms these indicators into new variables used as inputs. Some indicators can lead to more than one input, but in this work, we mapped each indicator to one input to keep the model simple and the fuzzy inference module which is based on the fuzzy rules and membership functions created. The rules were generated from experts and available literature on technical analysis. Two membership functions were defined for two input variables; MACD and OBV. For the other two, three membership functions were defined for each. Experiments were done with MATLAB using actual stock data of two Nigerian banks and showed satisfactory results. When the calculated recommendations were combined with other information and investing skills of an individual investor, the decision support system will be very valuable.

\section{References}

Achelis, S. B. (2000). Technical Analysis from A to Z (2nd ed.). New York, NY: McGraw-Hill.

Ahmed, A. G., Raaffat, S. E., \& Nevins, M. D. (2007). Stock Technical Analysis using Multi Agent and Fuzzy Logic. Proceedings of the World Congress on Engineering, 1, London, U. K.

Alcala, R., Casillas, J., Cordon, O., Herrera, F., \& Zwir, J. S. (1999). Techniques for Learning and Tuning Fuzzy Rule-Based Systems for Linguistic Modeling and Their Application Knowledge Engineering Systems, Techniques and Applications. C. T. Leondes (Ed.), Academic Press.

Alejandro, E., Juliano, M., \& Sebastian, M. (2013). A Technical Analysis Indicator Based on Fuzzy Logic. Electronic Notes on Theoretical Computer Science, 292, 27-37. 
http://dx.doi.org/10.1016/j.entcs.2013.02.003

Asakwa, T. K. (1990). Stock Market Prediction System with Modular Neural Networks. IEEE-INNS-ENNS International Joint Conference on Neural Networks, San Diego, CA, USA.

Bollerslev. (1986). Generalized Autoregressive Conditional Heteroskedasticity. Journal of Econometrics, 31, 307-327. http://dx.doi.org/10.1016/0304-4076(86)90063-1

Brock, W. L., J., \& LeBaron, B. (1992). Simple technical trading rules and the stochastic properties of stock. Journal of finance, 47, 1731 -1764. http://dx.doi.org/10.1111/j.1540-6261.1992.tb04681.x

Chen, P. C., \& Liu, C. H. (2008). A TSK type fuzzy based system for stock price prediction. Expert Systems with Application, 34(1), 135-144. http://dx.doi.org/10.1016/j.eswa.2006.08.020

Chen, S. H., \& Chung, C. L. (2005). Agent Based Computational modeling of the stock price-volume relation, Journal of Information Sciences, 170, 75-100. http://dx.doi.org/10.1016/j.ins.2003.03.026

Chen, A. S., Leung, M. T., \& Daouk, H. (2003). Application of neural networks to an emerging financial market: Forecasting and trading the Taiwan stock index. Computers and Operations Research, 30, 901-923. http://dx.doi.org/10.1016/S0305-0548(02)00037-0

Cheung, W. M., \& Uzay, K. (2007). A fuzzy logic based trading system. Proceedings of the Third European Symposium on Nature-Inspired Smart Information Systems, United Kingdom, 141-148.

Engel, \& Robert, F. (1982). Autoregressive Conditional Heteroskedasticity with Estimates of the Variance of United Kingdom Inflation. Econometrical, 50, 987- 1007. http://dx.doi.org/10.2307/1912773

Feng, L., Baowen, Li, Boris, P., Tobias, P., \& Eugene, H. (2012). Linking agent-based models and stochastic models of financial market. Preceding of the National Academy of Sciences of the United State of America, 109(22), 8388-8393. http://dx.doi.org/10.1073/pnas.1205013109

Fernández, R. F., González, M. C., \& Sosvilla, R. S. (2000). On the Profitability of Technical Trading Rules Based on Artificial Neural Networks: Evidence from the Madrid Stock Market. Economics Letters, 69, 89-94. http://dx.doi.org/10.1016/S0165-1765(00)00270-6

Halina, K., \& Marcin, C. (2001). Intelligent Techniques in Stock Analysis. Intelligent Information Systems, 195-208.

Hemanth, K. P., Prashant, K. B., Nirmala, T. V., \& Basavaraj, S. P. (2012). Neuro Fuzzy based Techniques for Predicting Stock, Trends. International Journal of Computer Science Issues, 9(3), 385-391.

Herrera, F., Lozano, M., \& Verdegay, J. L. (1994). Generating fuzzy rules from examples using genetic algorithm. proceedings of the fourth international conf. on Information Processing and Management of Uncertainty in Knowledge-based Systems, 675 -680. Paris France.

Hussein, D., \& Pepe, S. (2002). Investment using Technical Analysis and Fuzzy Logic. Fuzzy Sets and Systems, 127, 221-240. http://dx.doi.org/10.1016/S0165-0114(01)00169-5

Ince, H., \& Trafalis, T. B. (2008). Short term forecasting with support vector machines and application to stock price prediction. International Journal of General Systems, 37(6), 677-687. http://dx.doi.org/10.1080/03081070601068595

Jan, V. B., Uzay, K., \& Willien, M. B. (2004). Financial Markets Analysis Using a Probabilistic Fuzzy Modelling Approach. International Journal of Approximate Reasoning, 35(3), 291-305. http://dx.doi.org/10.1016/j.jjar.2003.08.007

Kato, T. (2012). Stock Price fluctuations in an agent-based model with market liquidity. Journal of Social Science. Research Network.

Kou, R. J., Chen, C. H., \& Hwang, Y. C. (2001). An Intelligent Stock Trading Decision Support System through Integration of Genetic Algorithm based Fuzzy Neural Network and Artificial Neural Network. Fuzzy Sets and Systems, 118, 21-45. http://dx.doi.org/10.1016/S0165-0114(98)00399-6

Li, J., \& Tsang, E. P. K. (1999). Improving Technical Analysis predictions: An Application of Genetic Programming. Proceedings of the $12^{\text {th }}$ International FLAIRS conference (FLAIRS-1999), USA.

Lin, C. T., \& Lee, G. (1996). Neural fuzzy systems: A neuro-fuzzy synergism to intelligent systems, Neural fuzzy systems: a neuro-fuzzy synergism to intelligent systems Prentice-Hall, Inc. Upper Saddle River, NJ, USA.

Lin, C. S., Khan, H. A., \& Huang, C. C. (2002). Can the neuro-fuzzy model predict stock indexes better than its 
rivals? CIRJE F-Series CIRJE-F-165, Faculty of Economics, University of Tokyo.

Lux, T., \& Marchesi, M. (2000). Volatility clustering in financial markets: a micro-simulation of financial agents. International Journal of Theoretical and Applied Finance, 3, 675-702. http://dx.doi.org/10.1142/S0219024900000826

Maniadakis, M., \& Suurmann, H. (1999). A Genetic Algorithm for Structural and Parametrical Tuning of Fuzzy Systems. European Symposium on Intelligent Techniques, ESIT99.

Melek, A. B., \& Derya, A. (2010). An Adaptive Network Based Fuzzy Inference System (ANFIS) for the Prediction of Stock market return: The case of Istanbul Stock Exchange. Expert Systems with Applications, 37, 7908-7912. http://dx.doi.org/10.1016/j.eswa.2010.04.045

Nicholis, S. C., \& Sumpter, D. J. T. (2011). A dynamical approach to stock market fluctuation. International Journal of Bifurcation and Chaos, 21(12), 3557 -564. http://dx.doi.org/10.1142/S0218127411030726

Ozun, A. (2006). Modeling chaotic behaviours in financial markets. Journal of Istanbul Kultur University, 181-187.

Palmer, R. G., Arthur, W. B., Holland, J. H., LeBaron, B., \& Tayler, P. (1994). Artificial Life: A Simple Model of a Stock Market. Journal of Physica D, 75, 264-274. http://dx.doi.org/10.1016/0167-2789(94)90287-9

Potvin, J. Y., Soriano, P., \& Vallée, M. (2004). Generating trading rules on the stock markets with genetic

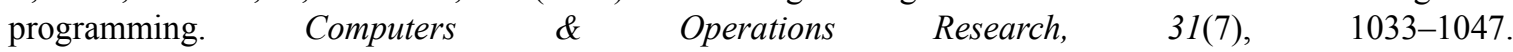
http://dx.doi.org/10.1016/S0305-0548(03)00063-7

Preethi, G., \& Santhi, B. (2012). Stock market forecasting techniques: A survey. Journal of Theoretical and Applied Information Technology.

Refenes, A. N., Burgess, N., \& Bentz, Y. (1997). Neural Networks in Financial Engineering: A Study in Methodology. IEEE Trans. Neural Networks, 8(6), 1222-1267. http://dx.doi.org/10.1109/72.641449

Shangkum, D., \& Sakurai, A. (2013). Foreign Exchange Trading Rules Using a Single Technical Indicator from Multiple Time Frames. International Conference on Advanced Information Networking and Applications Workshop (WAINA), 207-212.

Simutis. (2000). Fuzzy Logic Based Stock Trading System. Proceedings IEEE/IAFE conf. on Computational Intelligence of Financial Engineering, New York, 2000.

Sotiris, Z., Skiada, C., \& Jiannis, V. (1999). Technical Analysis and Mutual Funds Testing Trading rules. European Symposium on Intelligent Techniques, Orthodox Academy of Crete, Greece.

Tang, Y., Xu, X., Wan, \& Zhang, Y. (2002). Web Based Fuzzy Neural Networks for Stock Prediction. Proceding of $2^{\text {nd }}$ International Workshop on Intelligent Systems Design and Applications, 169-174.

Theodorus, Z., \& Dimitrus, K. (2013). Short Term Prediction of Foreign Exchange Rates with a Neural-Network Based Ensemble of Financial Technical Indicators. International Journal on Artificial Intelligence Tools, 22(3), 220-241.

Vincent, O. R., \& Bamiro, K. (2013). Fluctuations in Stock Market Prices: What went wrong, its Implications to Nigerian Economy. International Journal of Computer Applications, 63(19), 13-20. http://dx.doi.org/10.5120/10573-5612

Yates, J. F. (1990). Judgment and Decision Making. Prentice-Hall, Englewood Cliffs, NJ, 1990.

Yun, L., Baolong, Y., \& Hua, Z. (2013). A New Wrapped Ensemble Approach for Financial Forecast. Journal of Intelligent Systems, 23(1), 21-32.

Zhou, X. S., \& Don, M. (2004). Can fuzzy logic make technical analysis 20/20. Financial analyst journal, 60, 54-73. http://dx.doi.org/10.2469/faj.v60.n4.2637

Zou, L., Chaoqun, M. A., Yang, M. I., \& Zhongbao, Z. (2005). Chaos Evolution in an Order-driven Artificial Chinese Stock Market. Human Provincial Social Science Foundation of China.

\section{Copyrights}

Copyright for this article is retained by the author(s), with first publication rights granted to the journal.

This is an open-access article distributed under the terms and conditions of the Creative Commons Attribution license (http://creativecommons.org/licenses/by/3.0/). 